\title{
The dynamics of the Snowball Earth Hadley circulation for off-equatorial and seasonally varying insolation
}

\author{
A. Voigt \\ Laboratoire de Météorologie Dynamique, IPSL, CNRS/UPMC - UMR8539, Paris, France \\ Correspondence to: A. Voigt (aiko.voigt@1md.jussieu.fr) \\ Received: 27 August 2013 - Published in Earth Syst. Dynam. Discuss.: 29 August 2013 \\ Revised: 31 October 2013 - Accepted: 1 November 2013 - Published: 27 November 2013
}

\begin{abstract}
I study the Hadley circulation of a completely icecovered Snowball Earth through simulations with a comprehensive atmosphere general circulation model. Because the Snowball Earth atmosphere is an example of a dry atmosphere, these simulations allow me to test to what extent dry theories and idealized models capture the dynamics of realistic dry Hadley circulations. Perpetual off-equatorial as well as seasonally varying insolation is used, extending a previous study for perpetual on-equatorial (equinox) insolation. Vertical diffusion of momentum, representing the momentum transport of dry convection, is fundamental to the momentum budgets of both the winter and summer cells. In the zonal budget, it is the primary process balancing the Coriolis force. In the meridional budget, it mixes meridional momentum between the upper and the lower branch and thereby decelerates the circulation. Because of the latter, the circulation intensifies by a factor of three when vertical diffusion of momentum is suppressed. For seasonally varying insolation, the circulation undergoes rapid transitions from the weak summer into the strong winter regime. Consistent with previous studies in idealized models, these transitions result from a mean-flow feedback, because of which they are insensitive to the treatment of vertical diffusion of momentum. Overall, the results corroborate previous findings for perpetual on-equatorial insolation. They demonstrate that descriptions of realistic dry Hadley circulations, in particular their strength, need to incorporate the vertical momentum transport by dry convection, a process that is neglected in most dry theories and idealized models. An improved estimate of the strength of the Snowball Earth Hadley circulation will also help to better constrain the climate of a possible Neoproterozoic Snowball Earth and its deglaciation threshold.
\end{abstract}

\section{Introduction}

Geological evidence suggests that during the Neoproterozoic era (1000 to 541 million years before present), Earth might have repeatedly experienced global glaciations for many millions of years (Kirschvink, 1992; Hoffman et al., 1998; Hoffman and Schrag, 2000; Pierrehumbert et al., 2011). These glaciations are commonly referred to as Snowball Earth, a term inspired by the high albedo of such an Earth due to the hypothesized planetary-scale land glaciers and the completely sea-ice covered oceans. The global ice cover entails surface temperatures well below freezing and, as a consequence of the Clausius-Clapeyron equation, an atmosphere essentially devoid of water. The Snowball Earth atmosphere thus belongs to the class of dry atmospheres, which traditionally have formed the starting point for theories of the large-scale atmospheric circulation. In particular, dry theories have been developed for the Hadley circulation that dominates the zonal-mean circulation of Earth's tropics as well as other planets (Schneider, 2006).

Voigt et al. (2012) studied the dynamics of the Snowball Earth Hadley circulation using a comprehensive atmosphere general circulation model. Their primary motivation was to test to what extent dry Hadley cell theories are applicable to the Snowball Earth atmosphere and if the assumptions made by these theories are justified in the context of realistic dry atmospheres. The use of a comprehensive atmosphere model that embodies sophisticated representations of diabatic processes, such as radiation and small-scale turbulence, made their study complementary to previous work with idealized atmosphere models that represent diabatic processes in a simplified manner. Voigt et al. (2012) found that vertical diffusion of momentum, representing the dry turbulence and the 
momentum transport by small-scale (i.e. unresolved) eddies, is fundamental to the Snowball Earth Hadley circulation and weakens the circulation by a factor of 2 to 3 . This result is important because dry Hadley cell theories and idealized models usually neglect vertical diffusion of momentum and assume that the flow is governed by its resolved large-scale features. However, Voigt et al. (2012) used perpetual equinox solar insolation, with the insolation maximum centered at the equator and zero insolation at the poles, which might be a potential limiting factor for their results because the strength and dynamics of the Hadley circulation are known to change with the location of the insolation maximum. For example, Lindzen and Hou (1988) showed that the strength of the circulation increases non-linearly in axisymmetric models when the insolation maximum is displaced away from the equator. Moreover, Walker and Schneider (2005), comparing the Hadley circulation of an idealized axisymmetric model with that of an idealized general circulation model, found that large-scale eddies strengthen the circulation for an on-equatorial insolation maximum, while they weaken the winter and strengthen the summer circulation for an offequatorial insolation maximum. To address the question if the magnitude and effect of vertical diffusion on the Snowball Earth Hadley circulation shows a similar sensitivity to the insolation profile, I here expand the work of Voigt et al. (2012) to the cases of a perpetual off-equatorial insolation maximum as well as seasonally varying insolation. The primary goal of the present manuscript is to demonstrate that the results of Voigt et al. (2012) do not depend on the location of the solar insolation maximum. Independent of the solar insolation profile, vertical diffusion of momentum is important to the momentum budgets of the Snowball Earth Hadley circulation and substantially weakens the circulation.

The simulations presented here with seasonally varying insolation moreover connect to recent studies by Schneider and Bordoni (2008) and Bordoni and Schneider (2010) on rapid seasonal changes of the Hadley circulation in an idealized atmosphere general circulation model coupled to a low thermal inertia surface. Schneider and Bordoni (2008) and Bordoni and Schneider (2010) described a mean-flow feedback that, supported by eddies, enables transitions in the dominant momentum balance from an eddy-dominated summer and equinox regime to an angular-momentum conserving winter regime. In conjunction with the rapid changes in the Hadley cell strength and location, these circulations resembled the monsoons observed for today's Earth. The idealized atmosphere general circulation model used by Schneider and Bordoni (2008) and Bordoni and Schneider (2010), however, does not account for vertical diffusion of momentum, which raises the question to what extent vertical diffusion of momentum affects the rapid transitions.

Understanding the Hadley circulation of a Snowball Earth atmosphere is not only important for the development of Hadley cell theories. A better characterization of the climate during Snowball Earth episodes also helps to constrain the deglaciation threshold of a hard Snowball Earth and to judge to what extent proposed scenarios for the survival of life during such harsh conditions appear plausible. The low heat capacity of the ice surface allows large seasonal shifts of the Hadley circulation, yielding an indirect annual-mean circulation and, in contrast to Earth's modern climate, a zone of net evaporation around the equator (Abbot and Pierrehumbert, 2010; Pierrehumbert et al., 2011; Abbot et al., 2013). The equatorial net evaporation zone lowers the equatorial surface albedo because bare ice has a much lower albedo than snow (Brandt et al., 2005; Warren and Brandt, 2006; Dadic et al., 2013) and because of accumulation of surface dust. Both factors facilitate the deglaciation of a hard Snowball Earth (Abbot and Pierrehumbert, 2010; Le Hir et al., 2010). While the equatorial net evaporation zone emerges as a robust feature of climate models (Abbot et al., 2013), its detailed characteristics likely depend on the Hadley circulation. The Hadley circulation also affects other suggested deglaciation factors such as atmospheric dust (Abbot and Halevy, 2010) and tropical clouds (Abbot et al., 2012). Through its impact on the tropical precipitation minus evaporation pattern, the Hadley circulation furthermore influences the flow of thick sea ice and the possibility of open narrow seaways that could serve as oases for the survival of life during Snowball events (Campbell et al., 2011; Tziperman et al., 2012; Abbot et al., 2013). Finally, the Hadley circulation plays an important role during the initiation of Snowball Earth episodes (Voigt and Marotzke, 2010; Abbot et al., 2011; Voigt and Abbot, 2012; Yang et al., 2012a, b) during which it progressively approaches the dry limit discussed here. All of the above factors depend on the strength of the Hadley circulation, which Abbot et al. (2013) found to vary by up to a factor of 4 in annual-mean and a factor of 2 in solstice conditions among comprehensive atmosphere general circulation models driven by the same idealized Snowball Earth boundary conditions. The simulations presented here suggest that this difference might, at least partly, be caused by differences in the models' treatment of vertical diffusion of momentum.

The paper is organized as follows. The atmosphere general circulation model and the simulation setup are described in Sect. 2. The simulations with a perpetual off-equatorial insolation maximum are presented in Sect. 3; those with seasonally varying insolation in Sect. 4 . In both sections, the dynamics of the Hadley circulation are studied through an analysis of the zonal and meridional momentum budgets, and the effect of vertical diffusion of momentum on the Hadley circulation is investigated through simulations in which vertical diffusion of momentum is suppressed. Section 5 illustrates briefly how differences in the strength of the Hadley circulation translate to differences in the strength of the tropical hydrological cycle and equatorial net evaporation zone. The paper closes with conclusions in Sect. 6. 

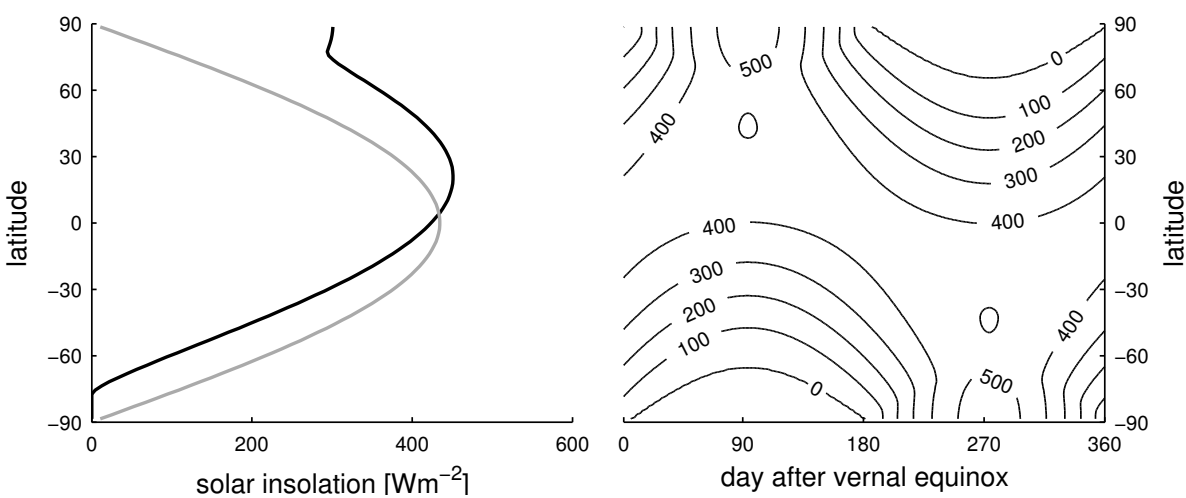

Fig. 1. Solar insolation at the top of atmosphere in $\mathrm{Wm}^{-2}$. Left panel: perpetual off-equatorial insolation with maximum at $23.5^{\circ} \mathrm{N}$. For reference, the symmetric equinox profile used in Voigt et al. (2012) is shown in gray. Right panel: seasonally varying insolation profile corresponding to a circular orbit with an obliquity of $23.5^{\circ}$. A 360 -day calendar is applied, with days counted from vernal equinox.

\section{Model and simulation setup}

I use the comprehensive atmosphere general circulation model ECHAM5 in idealized hard Snowball Earth conditions. The model and boundary conditions are the same as those used in in Voigt et al. (2012), apart from differences in the solar insolation profile. In contrast to Voigt et al. (2012) who used perpetual equinox insolation with solar insolation maximum at the equator, I here apply perpetual insolation with an off-equatorial solar insolation maximum as well as seasonally varying insolation (Fig. 1). The seasonally varying insolation corresponds to a circular orbit with $23.5^{\circ}$ obliquity. For the perpetual off-equatorial insolation profile, the insolation maximum is at $23.5^{\circ} \mathrm{N}$. This profile does not represent the solsticial insolation conditions of the seasonally varying insolation. Instead, it is chosen as one of many possible examples for off-equatorial insolation maxima and corresponds to the insolation at day 35 after vernal equinox of the seasonally varying simulations. Interestingly, it will turn out below that the rapid Hadley circulation transitions in the seasonally varying simulations are completed at day 35 , after which the Hadley circulation strength remains almost constant for 130 days. Because of this, the Hadley circulation for the perpetual off-equatorial insolation profile closely resembles that for solstitial conditions. A 360-day calendar is used.

For completeness, I briefly summarize the idealized hard Snowball Earth conditions. A more thorough description is given in Voigt et al. (2012). A modern solar constant of $1365 \mathrm{~W} \mathrm{~m}^{-2}$ is used. Atmospheric $\mathrm{CO}_{2}$ is set to $300 \mathrm{ppmv}$; $\mathrm{CH}_{4}, \mathrm{~N}_{2} \mathrm{O}, \mathrm{CFCs}$, ozone, and aerosols are all set to zero. Sea-ice albedo is set to 0.75 everywhere. These choices yield tropical surface temperatures of around $220 \mathrm{~K}$, and the simulated atmospheric conditions represent the very cold and essentially dry conditions during the early stage of a hard Snowball Earth glaciation. The low temperatures entail low atmospheric water vapor; the global-mean atmosphere water vapor content and surface latent heat flux are 0.01 and $0.1 \mathrm{~W} \mathrm{~m}^{-2}$, respectively, which is three orders of magnitude smaller than in present-day Earth simulations with the same model. This makes the simulated Snowball Earth atmosphere an example of a virtually dry atmosphere in which latent heating and moist convection have no substantial effect on the circulation.

The surface is specified as $0.1 \mathrm{~m}$-thick ice, yielding a small thermal inertia of the surface and thereby allowing rapid Hadley cell transitions as in Schneider and Bordoni (2008). Surface temperature is predicted from the sum of radiative (longwave and shortwave) and turbulent (sensible and latent heat) fluxes and the surface heat capacity; conductive heat flux through ice is assumed to be zero. This setup is equivalent to a thin "white" mixed-layer ocean without ocean heat transport. A flat surface with no orography is applied, eliminating mountain-induced stationary eddies that could affect the Hadley circulation. Surface roughness length is set to $10^{-3} \mathrm{~m}$ everywhere. Diurnally averaged insolation is applied. This is motivated by the fact that Hadley cell theories do not incorporate the diurnal cycle and furthermore helps to avoid overestimating the diurnal surface temperature cycle due to insufficient vertical resolution of the ice layer (Abbot et al., 2010). Horizontal resolution is $\mathrm{T} 63\left(1.75^{\circ}\right)$ with 31 unevenly spaced hybrid $\sigma$-levels in the vertical. The model is integrated for $20 \mathrm{yr}$, with statistics calculated from the last 5 yr. Table 1 summarizes the simulations.

\section{Perpetual off-equatorial insolation maximum}

\subsection{Characteristics and momentum budgets of the Hadley circulation}

I start with studying the Hadley circulation for perpetual insolation with maximum solar heating at $23.5^{\circ} \mathrm{N}$. The primary purpose of this section is to show that vertical diffusion of momentum remains important for the Hadley cell dynamics 

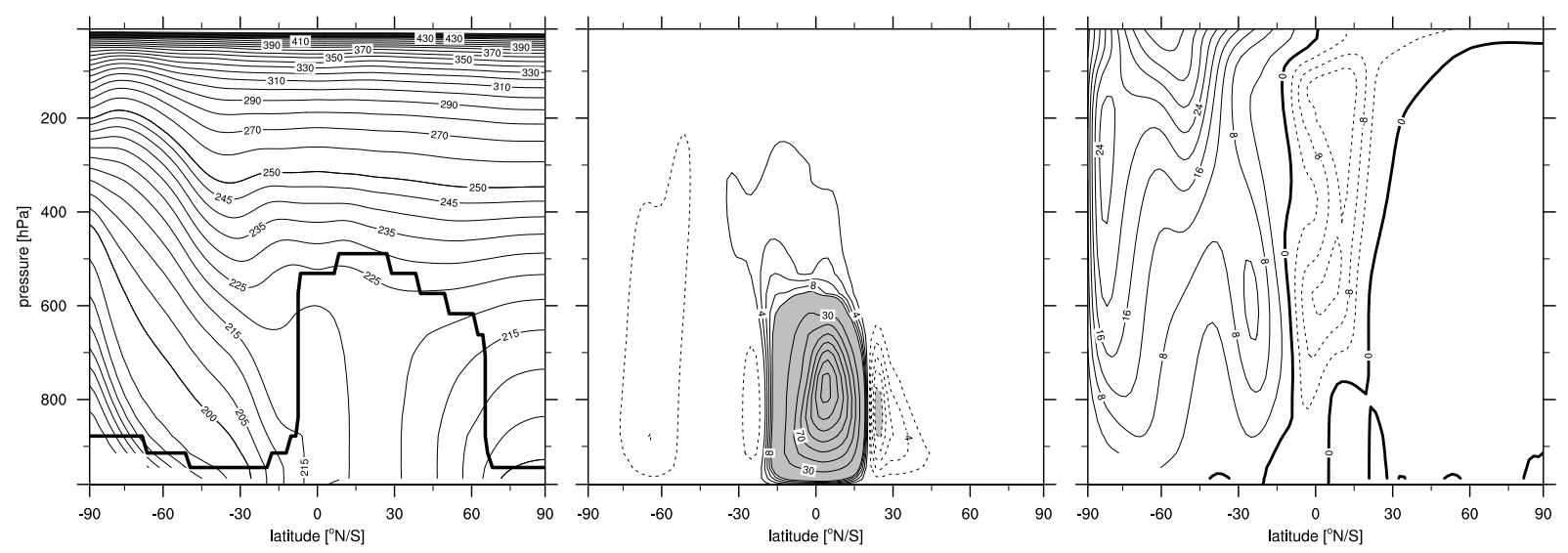

Fig. 2. Zonal-mean circulation of the Snowball Earth atmosphere for perpetual off-equatorial insolation. Left panel: potential temperature in $\mathrm{K}$. Contour interval is $5 \mathrm{~K}$ between 200,250 and $10 \mathrm{~K}$ otherwise. The black solid line depicts the tropopause (see text). Middle panel: mass stream function in units of $10^{9} \mathrm{~kg} \mathrm{~s}^{-1}$. Solid (dashed) contour lines represent counterclockwise (clockwise) circulation. Contour interval is 2 between -10 and 10, and 20 otherwise (gray shading). Left panel: zonal wind in $\mathrm{m} \mathrm{s}^{-1}$. Contour interval is 4 , with a thick zero contour line.

of a Snowball Earth atmosphere also when the insolation maximum is displaced away from the equator.

The insolation maximum at $23.5^{\circ} \mathrm{N}$ leads to a surface temperature maximum of $220 \mathrm{~K}$ at this latitude (Fig. 2). Around this latitude, potential temperatures are vertically uniform from the surface up to $500 \mathrm{hPa}$. The tropopause, defined as the lowest level for which the vertical potential temperature gradient exceeds $4 \mathrm{~K} \mathrm{~km}^{-1}$ (Voigt et al., 2012), resides at $500 \mathrm{hPa}$. The tropopause is around $500 \mathrm{hPa}$ also in the midlatitudes of the summer hemisphere but is close to the surface in the high latitudes and the entire winter hemisphere, where a surface inversion forms ${ }^{1}$. The Hadley circulation consists of a strong winter cell and a much weaker summer cell. The center of the ascending region is located equatorward of the insolation maximum at $15^{\circ} \mathrm{N}$. The winter cell attains its maximum of $156 \times 10^{9} \mathrm{~kg} \mathrm{~s}^{-1}$ in the summer hemisphere at $3^{\circ} \mathrm{N}$. As in the case of equinox insolation (Voigt et al., 2012), the winter cell extends up to $500 \mathrm{hPa}$ and is embedded into a deep weak cell that reaches up to $200 \mathrm{hPa}$. The summer cell attains its maximum of $11 \times 10^{9} \mathrm{~kg} \mathrm{~s}^{-1}$ at the maximum of the solar insolation at $23.5^{\circ} \mathrm{N}$. The winter and summer cells separate at $20^{\circ} \mathrm{N}$. While the winter cell is broad, covering about $30^{\circ}$ latitude, the summer cell is not only much weaker but also confined to a much narrower latitude band. Zonal winds are generally weak in the summer hemisphere, consistent with weak baroclinicity there. Stronger winds occur in the winter hemisphere, where winds are generally westerly and a subtropical jet develops at the poleward boundary of the winter cell. Upper-level easterlies of up to $12 \mathrm{~m} \mathrm{~s}^{-1}$ pertain close to the equator.

\footnotetext{
${ }^{1}$ Because the insolation maximum is located in the Northern Hemisphere, I will refer to this hemisphere as the summer hemisphere, and to the Southern Hemisphere as the winter hemisphere. I will use the same terminology for the northern and southern cells of the Hadley circulation.
}

Table 1. Summary of simulations with different treatment of vertical diffusion of momentum. All simulations are performed for perpetual off-equatorial as well as seasonally varying insolation. The last column indicates whether full or suppressed eddy viscosities are used for the calculation of turbulent kinetic energy (TKE). See text for details.

\begin{tabular}{llll}
\hline Simulation & \multicolumn{3}{c}{ Vertical diffusion of } \\
\cline { 2 - 4 } & $\begin{array}{l}\text { Zonal } \\
\text { momentum }\end{array}$ & $\begin{array}{l}\text { Meridional } \\
\text { momentum }\end{array}$ & TKE \\
\hline STD & on & on & on \\
U0V0T1 & off & off & on \\
U0V0T0 & off & off & off \\
U0V1T1 & off & on & on \\
U0V1T0 & off & on & off \\
U1V0T1 & on & off & on \\
U1V0T0 & on & off & off \\
\hline
\end{tabular}

In steady state, the zonal-mean zonal momentum budget in pressure coordinates reads

$\frac{\partial \bar{u}}{\partial t}=0=f \bar{v}+\bar{\zeta} \bar{v}-\bar{\omega} \frac{\partial \bar{u}}{\partial p}-\frac{1}{a \cos ^{2} \varphi} \frac{\partial\left(\overline{u^{\prime} v^{\prime}} \cos ^{2} \varphi\right)}{\partial \varphi}-\frac{\partial \overline{u^{\prime} w^{\prime}}}{\partial p}+D^{u}$.

$D^{u}$ denotes the zonal-mean zonal momentum tendency due to vertical diffusion. Vertical diffusion represents the momentum transport by dry convection, which results from subgrid-scale dry eddies in response to unstable stratification and vertical wind shear. The notation is standard otherwise. In the Snowball Earth atmosphere, moist convection and horizontal diffusion do not substantially affect the zonal momentum budget, which is why they are not included in the above equation.

Vertical diffusion is of first-order importance to the Hadley circulation (Fig. 3). The summer cell is in viscous balance, 

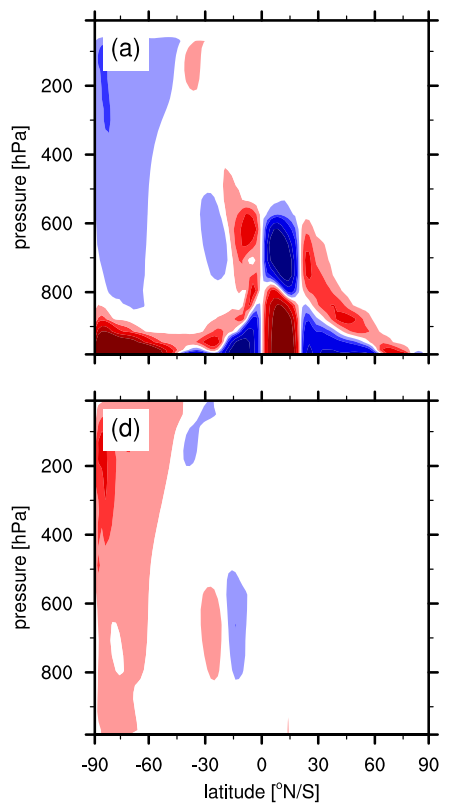
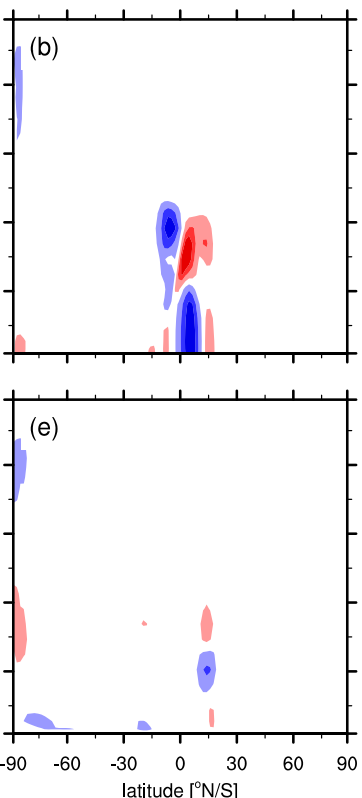

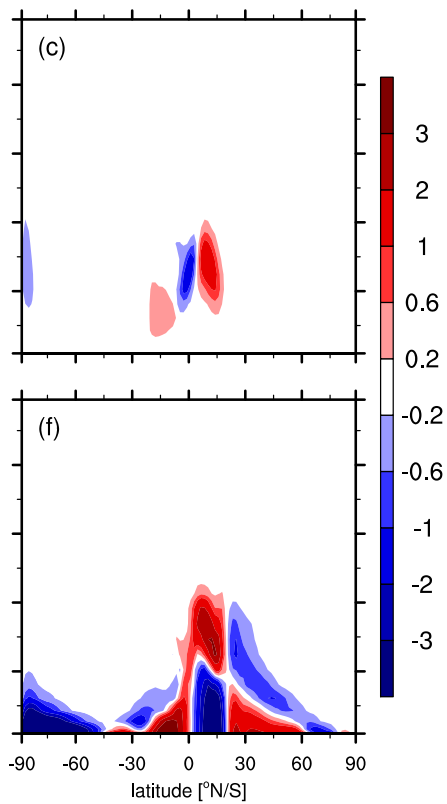

Fig. 3. Zonal-mean zonal momentum budget for perpetual off-equatorial insolation in $10^{-5} \mathrm{~m} \mathrm{~s}^{-2}$ : (a) Coriolis force, (b) meridional advection of mean relative vorticity, (c) negative of vertical advection of mean zonal momentum, (d) horizontal contribution to eddy momentum flux convergence, (e) vertical contribution to eddy momentum flux convergence, and (f) vertical diffusion of zonal momentum. The contributions from moist convection (i.e. cumulus friction) and horizontal diffusion are negligible.

$f \bar{v}+D^{u} \simeq 0$. Vertical diffusion is also important for the winter cell, although the winter cell shows a more complex momentum budget. In the summer hemisphere, vertical diffusion is the primary process balancing the Coriolis force in the upper branch, with smaller contributions from the mean circulation. In the winter hemisphere, however, vertical diffusion is suppressed in the upper branch. Instead, meridional advection of mean relative vorticity dominates and the cell is close to angular-momentum conservation, $(f+\bar{\zeta}) \bar{v} \simeq 0$. Eddies are negligible for both the winter cell, as a result of easterly winds that shield the upper branch from the influence of the mid-latitude eddies of the winter hemisphere (Charney, 1969; Webster and Holton, 1982), and the summer cell, because baroclinicity and eddy activity are essentially zero there, consistent with the small meridional temperature gradients.

The dominant role of vertical diffusion on the strength of the Hadley circulation can be demonstrated by decomposing the strength of the winter and summer cells into contributions from the mean circulation, eddies, and vertical diffusion. Following Schneider and Bordoni (2008) and Bordoni and Schneider (2010), I do this by rewriting the zonal momentum balance as

$\bar{v}=-\frac{1}{f}\left(M+E+D^{u}\right)$.

$M=\bar{\zeta} \bar{v}-\bar{\omega} \frac{\partial \bar{u}}{\partial p}$ and $E=-\frac{1}{a \cos ^{2} \varphi} \frac{\partial\left(\overline{u^{\prime} v^{\prime}} \cos ^{2} \varphi\right)}{\partial \varphi}-\frac{\partial \overline{u^{\prime} w^{\prime}}}{\partial p}$ denote the momentum flux convergence due to the mean circulation and eddies, respectively. For a cell that attains its maximum $\Psi$ at latitude $\varphi_{0}$ and pressure $p_{0}$, the definition of the mass stream function, $\Psi=-\frac{2 \pi a \cos \varphi_{0}}{g} \int_{0}^{p_{0}} \bar{v}\left(\varphi_{0}, p\right) \mathrm{d} p$ allows to decompose $\Psi$ into a mean, an eddy, and a diffusive component,

$\Psi=\Psi_{\mathrm{M}}+\Psi_{\mathrm{E}}+\Psi_{\mathrm{D}}$

The mean component is defined as

$\Psi_{\mathrm{M}}=\frac{2 \pi a \cos \varphi_{0}}{f_{0} g} \int_{0}^{p_{0}} M\left(\varphi_{0}, p\right) \mathrm{d} p$,

where $f_{0}$ denotes the value of the Coriolis parameter at latitude $\varphi_{0}$; analogous expressions hold for the other components. Table 2 shows that vertical diffusion of zonal momentum carries the entire strength of the summer cell and most of the winter cell.

Vertical diffusion not only impacts the zonal momentum budget but also the meridional momentum budget of the Hadley circulation. While the flow is in geostrophic balance throughout most of the atmosphere, the meridional momentum tendency due to vertical diffusion of meridional momentum approaches values comparable to those for the Coriolis force and the geopotential gradient in the region of the winter and summer cell. Therefore, and as in the case of equinox insolation, the meridional momentum budget is approximately given by

$f \bar{u} \simeq-\frac{1}{a} \frac{\partial \bar{\Phi}}{\partial \varphi}+D^{v}$, 
Table 2. Simulations with perpetual off-equatorial insolation and different treatment of vertical diffusion of momentum: strength of the winter and summer Hadley cell and decomposition into contributions from the mean circulation $\left(\Psi_{\mathrm{M}}\right)$, eddies $\left(\Psi_{\mathrm{E}}\right)$, and vertical diffusion $\Psi_{\text {vdiff }}$ ). The attribution is based on Eq. (3) and accurate to within $5 \%$ of the cell strength as indicated by the residuum ( $\left.\Psi_{\text {res }}\right)$. All values in units of $10^{9} \mathrm{~kg} \mathrm{~s}^{-1}$.

\begin{tabular}{lrrrrr}
\hline Simulation & $\Psi$ & $\Psi_{\mathrm{M}}$ & $\Psi_{\mathrm{E}}$ & $\Psi_{\mathrm{D}}$ & $\Psi_{\text {res }}$ \\
\hline Summer cell \\
STD & 11 & 0 & 0 & 11 & 0 \\
U0V0T1 & 2 & 0 & 0 & 1 & 1 \\
U0V0T0 & 2 & 0 & 0 & 2 & 0 \\
U0V1T1 & 3 & 0 & 1 & 2 & 0 \\
U0V1T0 & 3 & 0 & 1 & 2 & 0 \\
U1V0T1 & 38 & 1 & 1 & 37 & -1 \\
U1V0T0 & 37 & 2 & 1 & 35 & -1 \\
\hline & \multicolumn{1}{c}{ Winter cell } & & \\
\hline STD & 156 & 27 & 7 & 117 & 5 \\
U0V0T1 & 439 & 269 & 145 & 0 & 25 \\
U0V0T0 & 288 & 133 & 141 & 0 & 14 \\
U0V1T1 & 196 & 120 & 87 & 0 & -11 \\
U0V1T0 & 158 & 55 & 100 & 0 & 3 \\
U1V0T1 & 431 & 98 & 8 & 320 & 5 \\
U1V0T0 & 334 & 123 & 9 & 195 & 7 \\
\hline
\end{tabular}

where $\Phi$ denotes the geopotential. Vertical diffusion of meridional momentum exhibits a distinct spatial pattern that coincides with the structure of the Hadley circulation (Fig. 4). This pattern implies that vertical diffusion mixes meridional momentum between the upper and lower branches of the circulation.

The temperature tendencies in the region of maximum insolation are shown in Fig. 5. Above the tropopause at $500 \mathrm{hPa}$ the atmosphere is close to radiative equilibrium, with nearly zero radiative heating rate. Within the troposphere, which extends from the surface up to $500 \mathrm{hPa}$, however, the main balance is between longwave radiative cooling and heating by vertical diffusion. The heating by vertical diffusion includes a very small and negligible contribution from dissipative heating, which ensures that the vertical diffusion scheme conserves energy. Temperature tendencies from other processes are comparably small: the near lack of atmospheric moisture implies only small latent heat release, and vertical advection has no effect on temperature because of the dryadiabatic temperature profile. Horizontal temperature transport by the Hadley circulation provides some heating in the upper troposphere by displacing isentropes from the vertical, which enables the dry Hadley circulation to transport energy (Caballero et al., 2008; Voigt et al., 2012). Overall, however, the troposphere is close to a radiative-convective equilibrium. Absorption of solar radiation at the surface leads

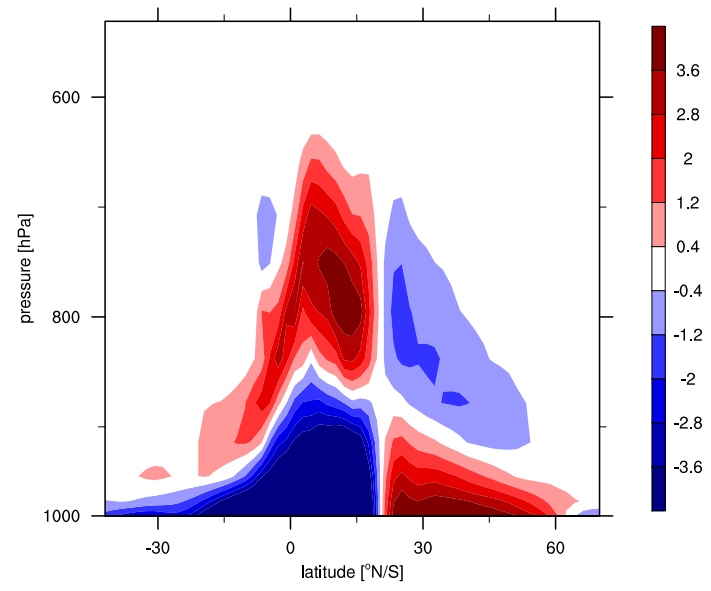

Fig. 4. Zonal-mean meridional momentum tendency due to vertical diffusion of meridional momentum in $10^{-5} \mathrm{~m} \mathrm{~s}^{-2}$ for perpetual offequatorial insolation.

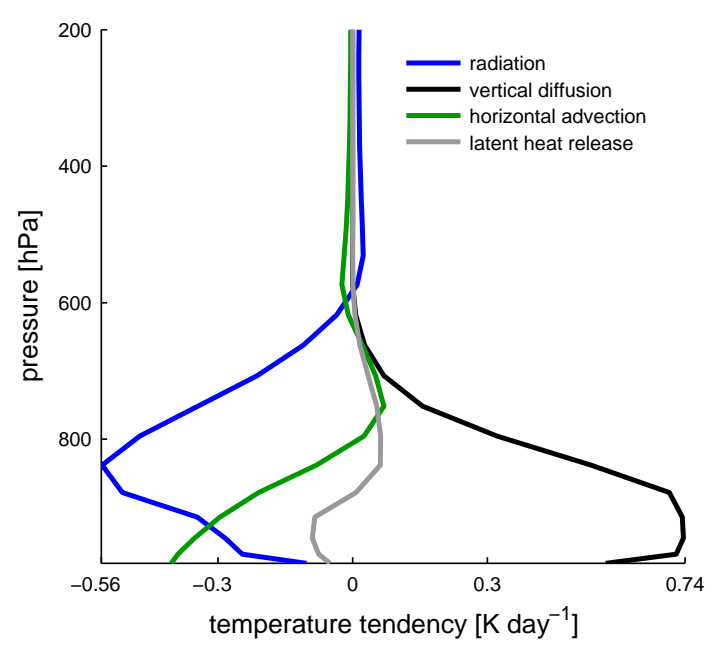

Fig. 5. Temperature tendencies for perpetual off-equatorial insolation in the region of maximum solar heating, between 15 and $30^{\circ} \mathrm{N}$. Vertical advection of temperature is negligible because temperatures are close to the dry adiabat.

to strong surface sensible heat and buoyancy fluxes, reaching about $20 \mathrm{~W} \mathrm{~m}^{-2}$ at the insolation maximum. This nearsurface destabilization of the troposphere causes dry convection, which explains the strong presence of vertical diffusion and the dry adiabatic temperature profile. The longwave radiative cooling balances the upward transport of dry static energy by dry convection. The magnitude of dry convection would be increased if longwave radiative cooling destabilized the troposphere on its own, i.e. in the absence of upward energy transport by dry convection. Similarly, atmospheric solar absorption could stabilize the troposphere, which would limit the dry convective activity. Pure-radiative equilibrium simulations would be needed to test and quantify these effects. 


\subsection{Impact of vertical diffusion of momentum on the strength of the Hadley circulation}

The pivotal role of vertical diffusion in the momentum budgets of the Hadley circulation motivates the study of how vertical diffusion of momentum impacts the strength of the circulation. To this end, I perform simulations in which vertical diffusion of momentum is suppressed in the upper branches of the Hadley circulation. To clarify whether vertical diffusion of zonal or meridional momentum is more important to the circulation strength, I furthermore perform simulations with vertical diffusion suppressed only for either zonal or meridional momentum. Such an investigation is warranted by the expected opposing effects of vertical diffusion of zonal and meridional momentum (Voigt et al., 2012). The zonal momentum budget suggests that the circulation is driven by vertical diffusion of zonal momentum, based on which one expects that suppressing vertical diffusion would weaken the circulation. In contrast, the meridional momentum budget suggests that vertical diffusion of momentum decelerates the circulation by mixing meridional momentum between the upper and lower branches. This suggests that suppressing vertical diffusion might lead to a stronger circulation.

To suppress vertical diffusion of momentum in the upper Hadley cell branches, I follow the approach of Voigt et al. (2012) and set eddy viscosities to zero above $870 \mathrm{hPa}$. Vertical diffusion of dry static energy remains active throughout the atmosphere, i.e. eddy diffusivities remain untouched. While being readily implemented, the approach leads to an ambiguity in the calculation of turbulent kinetic energy (TKE), which is used to calculate eddy diffusivity and viscosity. To show that the qualitative results are not sensitive to this ambiguity, I perform simulations in which TKE is calculated with either the full or the suppressed eddy viscosity (see Voigt et al., 2012, for details).

Simulations with suppressed vertical diffusion of momentum confirm that vertical diffusion strongly affects the strength of the Hadley circulation. In these simulations the winter cell intensifies by a factor of two to three, depending on how TKE is treated (Tables 1 and 2). This suggests that the climate model spread in the strength of the Snowball Earth Hadley cell strength found in Abbot et al. (2013) might be caused by differences in the models' treatment of vertical diffusion of momentum. The intensification results from the decelerating effect of vertical diffusion of meridional momentum, which is clearly demonstrated by simulations in which vertical diffusion of only meridional momentum is suppressed. The impact of vertical diffusion of zonal momentum on the strength of the winter cell is much smaller. The strength of the winter cell only changes marginally and even slightly intensifies when vertical diffusion of only zonal momentum is suppressed, in contrast to what one expects from the zonal momentum budget. The intensification is possible because increases in the momentum transport by horizontal and, to a lesser extent, vertical eddies compensate the loss of vertical diffusion in the zonal momentum budget. These eddies have small horizontal length scales of about $2000 \mathrm{~km}$ and are confined to the equatorial region, i.e. they are not of mid-latitude origin. They appear in conjunction with more easterly winds in the equatorial upper branch of the winter cell, suggesting that they originate from barotropic instability. Similar equatorial eddies occurred in the winter cells of Schneider and Bordoni (2008). The fact that these eddies only occur when vertical diffusion of zonal momentum is suppressed further exemplifies how parameterized diabatic processes can affect characteristics of the resolved large-scale circulation.

In contrast to the winter cell, the presence of vertical diffusion of momentum is crucial to the very existence of the summer cell. Vertical diffusion of meridional momentum decelerates also the summer cell, which triples in strength in simulations in which vertical diffusion of only meridional momentum is suppressed. However, the summer cell collapses as soon as vertical diffusion of zonal momentum is suppressed. This collapse is unavoidable because the nearzero baroclinicity and uniform zonal wind in the summer hemisphere prevent eddies and the mean circulation to compensate the loss of vertical diffusion in the zonal momentum budget.

Combined with the earlier equinox results of Voigt et al. (2012), these simulations establish that vertical diffusion of momentum strongly impacts steady-state Hadley circulations independent of whether the insolation maximum is located on or off the equator.

\section{Seasonally varying insolation}

This section studies the dynamics of the Snowball Earth Hadley circulation for seasonally varying insolation. I repeat the simulations using a seasonal cycle in insolation as specified in Fig. 1 to determine to what extent the results for timeconstant insolation carry over to time-varying insolation.

\subsection{Seasonal Hadley circulation, rapid transitions and associated momentum balances}

During most of the year, the circulation is dominated by either the southern or the northern cell, depending on the sun's location (Fig. 6, top panel). From day 35 to 180 (counted from vernal equinox), when the sun is in the Northern Hemisphere, the southern cell is in the vigorous winter regime. The strength and location of the southern cell match those simulated for perpetual off-equatorial insolation: the stream function maximum of $160 \mathrm{~kg} \mathrm{~s}^{-1}$ is located in the Northern Hemisphere, and the cell extends from $30^{\circ} \mathrm{N}$ to $30^{\circ} \mathrm{S}$ (Fig. 6, middle panel). During the same period, the northern cell experiences the weak summer regime, with stream function values close to or equal to zero. Indeed, between day 80 to 160 , the northern cell is collapsed. Reverse conditions occur 180 days 


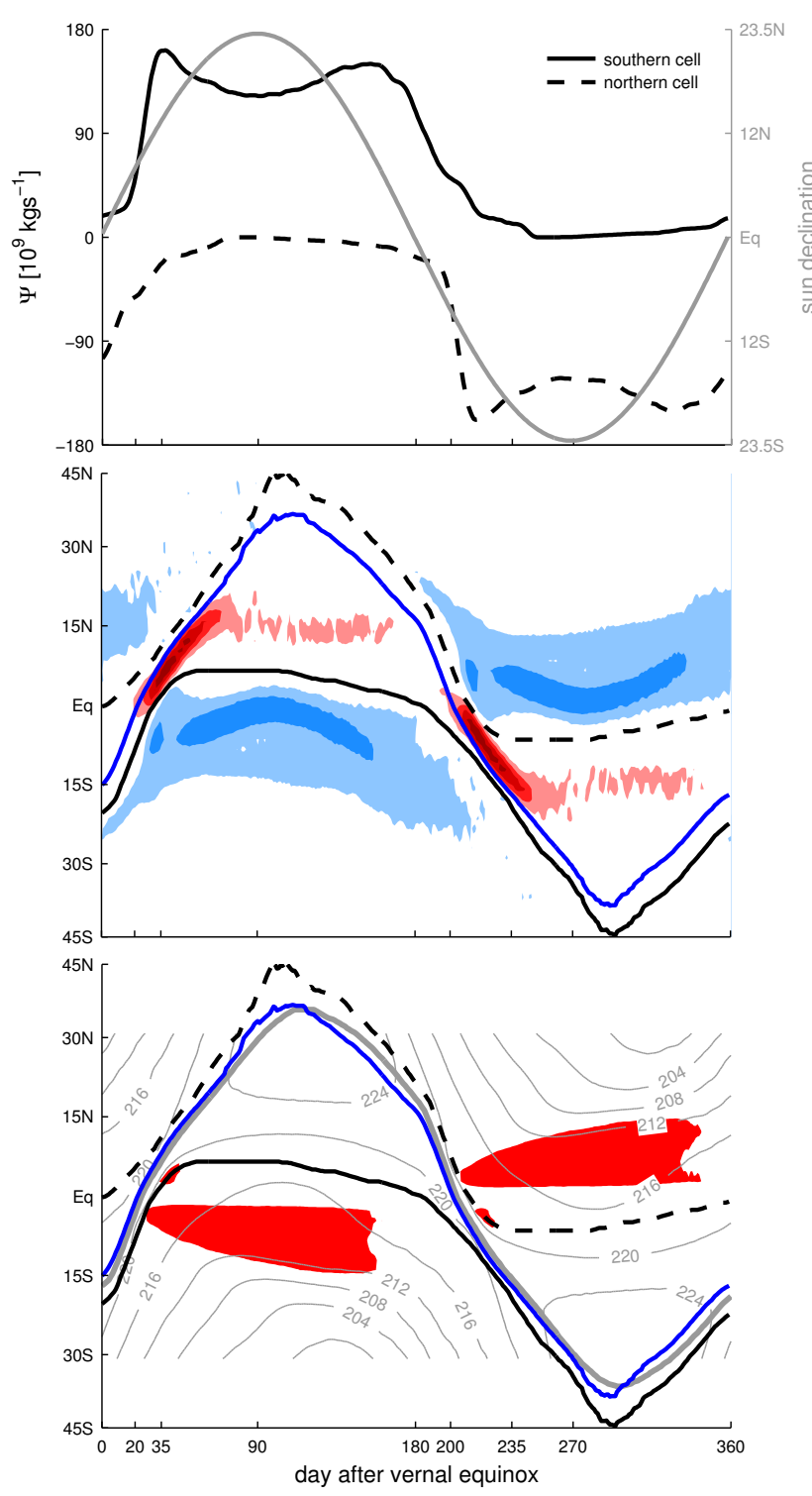

Fig. 6. Hadley circulation characteristics for seasonally varying insolation. Top panel: strength of the southern and northern cell in units of $10^{9} \mathrm{~kg} \mathrm{~s}^{-1}$. The sun declination in gray indicates the position of the sun. Middle panel: vertical mass flux $W=-\frac{2 \pi a \cos \varphi}{g} \omega$ at $800 \mathrm{hPa}$ in colored contours with contour interval of $40 \times 10^{4} \mathrm{~kg} \mathrm{~m}^{-1} \mathrm{~s}^{-1}$; upward mass flux in red, downward mass flux in blue. Bottom: Potential temperature (gray contours) and its maximum (thick gray) at $900 \mathrm{hPa}$. Regions with local Rossby numbers above 0.7 at $700 \mathrm{hPa}$ are shaded in red; note that regions in between $2^{\circ} \mathrm{N} / \mathrm{S}$ are masked as the Coriolis parameter is zero at the equator. The black and blue lines in the middle and bottom figures track the center of the northern (black dashed) and the southern cell (black solid) and the boundary between the two (blue solid). later between day 215 to 360 when the sun is in the Southern Hemisphere.

The Hadley circulation exhibits rapid transitions between states in which either the southern or the northern cell dominates. These transitions are so fast that the Hadley circulation in fact flips between these two states, yielding a square-wave dependence of the Hadley circulation strength on time. For example, at vernal equinox, the southern cell is in the weak summer regime, in which it remains until day 20 . Thereafter, however, the southern cell transitions into the vigorous winter regime in only 15 days. At day 35 , it has grown to its full strength and shifted its center into the Northern Hemisphere. The rapid transition is much faster than the change in solar insolation and manifests also in northward displacements of the vertical mass flux, the boundary between the southern and northern cell and the latitude of the maximum low-level potential temperature (Fig. 6, middle and bottom panels). In contrast, the collapse from the winter regime into the summer regime is slow. In terms of the cell strength, the collapse takes 75 days (from day 160 to 235), which is five times longer than the buildup. The different timescales are explained by differences in the momentum budgets during the build-up and collapse as will be shown later in the section.

Because of the square-wave dependence of the circulation strength on time, many of the circulation characteristics found for perpetual off-equatorial insolation also apply to the solstitial circulation, which I here calculate as the July circulation from day 100 to 130 . The tropopause in the summer hemisphere extends to about $500 \mathrm{hPa}$; potential temperatures are vertically uniform below (Fig. 7). The counterclockwise southern cell dominates the circulation, with easterlies prevailing in its upper branch. In the zonal momentum budget, the Coriolis force is primarily balanced by vertical diffusion of zonal momentum in the summer hemisphere (Fig. 8). In the winter hemisphere, the winter cell approximately conserves angular momentum, which is manifest in local Rossby numbers close to one ${ }^{2}$ (Fig. 6, bottom panel). In the meridional momentum budget, vertical diffusion of meridional momentum mixes meridional momentum between the upper and lower branches, with magnitudes similar to the perpetual offequatorial insolation (not shown). The solstitial circulation and the circulation for perpetual off-equatorial insolation differ in the high northern latitudes, but these differences are readily understood from differences in the insolation profile ${ }^{3}$. For example, the insolation maximum at the north pole in the solstitial conditions leads to a higher tropopause there and a weak counterclockwise cell, which is visible in the Coriolis term of the zonal momentum budget.

\footnotetext{
${ }^{2}$ The local Rossby number is defined as $R o=-\bar{\zeta} / f$ (Schneider, 2006).

${ }^{3}$ During solstice, the insolation exhibits maxima at $45^{\circ} \mathrm{N}$ and the north pole, with a fairly flat profile in between. The offequatorial insolation used in Sect. 3 maximizes at $23.5^{\circ} \mathrm{N}$ and drops to lower values further poleward.
} 

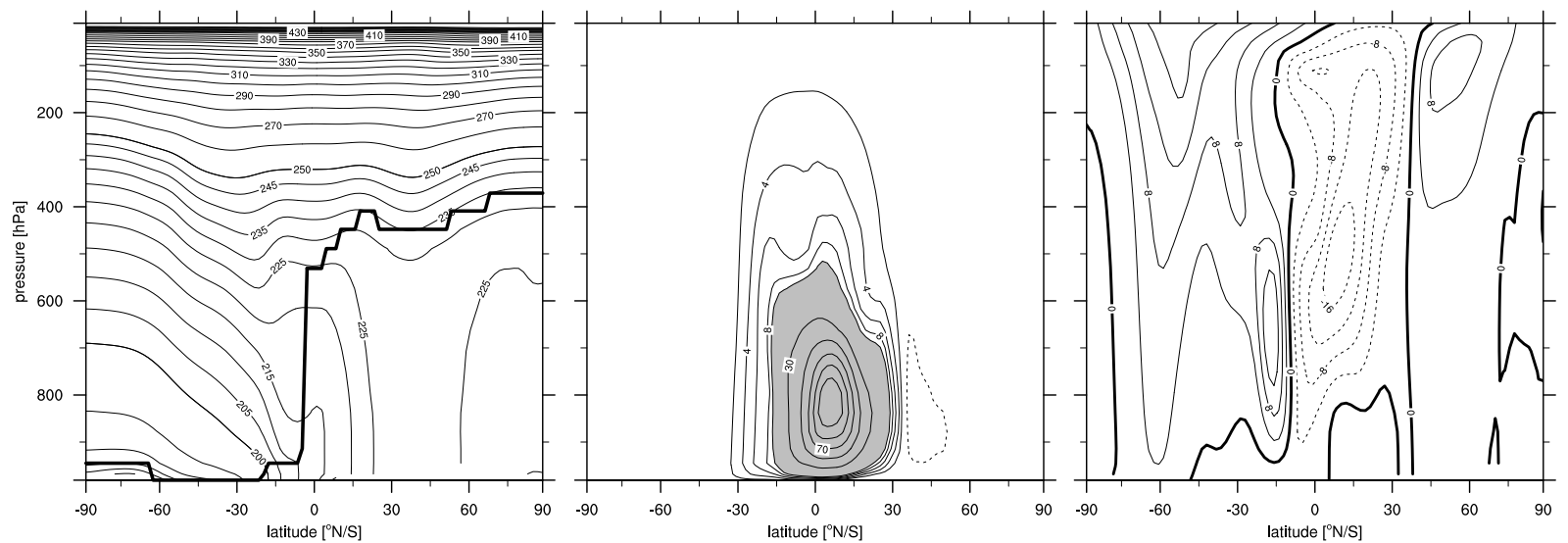

Fig. 7. Zonal-mean circulation for seasonally varying insolation during solstitial conditions in July (day 100-130). Left panel: potential temperature in $\mathrm{K}$. Contour interval is $5 \mathrm{~K}$ between 200 , 250 and $10 \mathrm{~K}$ otherwise. The black solid line depicts the tropopause (see text). Middle panel: mass stream function in units of $10^{9} \mathrm{~kg} \mathrm{~s}^{-1}$. Solid (dashed) contour lines represent counterclockwise (clockwise) circulation. Contour interval is 2 between -10 and 10 , and 20 otherwise (gray shading). Left panel: zonal wind in $\mathrm{m} \mathrm{s}^{-1}$. Contour interval is 4 , with a thick zero contour line.
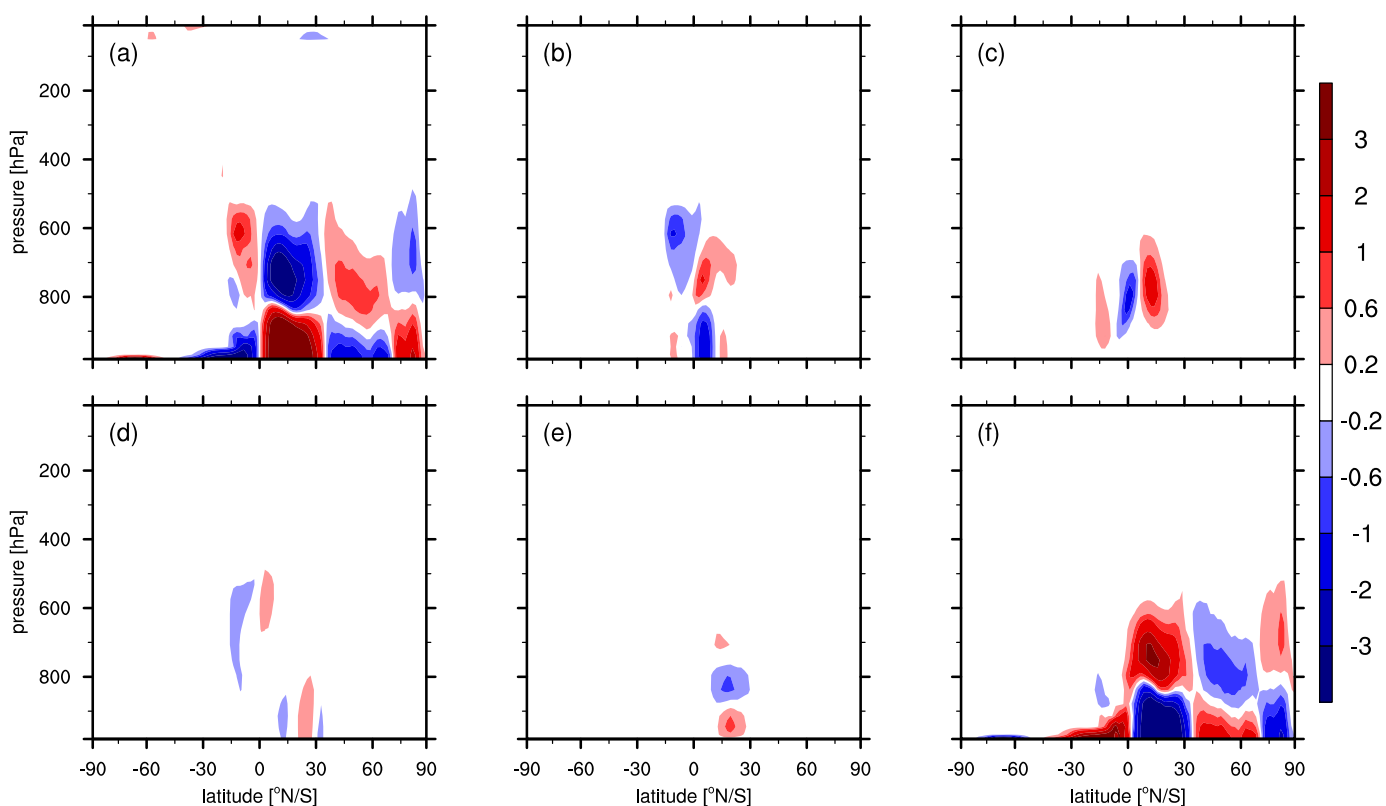

Fig. 8. Zonal-mean zonal momentum budget for seasonally varying insolation during solstitial conditions in July (day 100-130) in $10^{-5} \mathrm{~m} \mathrm{~s}^{-2}$ : (a) Coriolis force, (b) meridional advection of mean relative vorticity, (c) negative of vertical advection of mean zonal momentum, (d) horizontal contribution to eddy momentum flux convergence, (e) vertical contribution to eddy momentum flux convergence, and (f) vertical diffusion of zonal momentum. The contributions from moist convection (i.e. cumulus friction) and horizontal diffusion are negligible. The zonal wind is in approximately steady state in July, so that its time tendency is small during this period.

To decipher which processes are most important to the strength of Hadley circulation, I use the decomposition of the zonal momentum budget applied in Sect. 3. Because the Hadley circulation is dominated by the winter cell, I restrict the analysis to the southern cell and the period between days 0 and 235. During this period, the southern cell experiences the rapid transition into the vigorous winter regime, the fully developed status as winter cell, and the collapse to the weak summer regime. Time tendencies of the zonal wind above the winter cell maximum need to be taken into account, which is done by augmenting Eq. (3) by the inertial term, $\Psi_{\mathrm{I}}$,

$$
\Psi_{\mathrm{I}}=\frac{2 \pi a \cos \varphi_{0}}{f_{0} g} \int_{0}^{p_{0}} \frac{\partial \bar{u}}{\partial t} \mathrm{~d} p .
$$


The resulting decomposition,

$\Psi=\Psi_{\mathrm{M}}+\Psi_{\mathrm{E}}+\Psi_{\mathrm{D}}+\Psi_{\mathrm{I}}$,

is calculated for consecutive pentads at the latitude of the center of the winter cell, which moves in time.

In the fully developed phase of the winter regime, vertical diffusion is the most important contributor to the cell strength, carrying more than half of the cell strength (Fig. 9, left panel). The mean circulation is the second-largest contributor. Eddies affect the cell strength only marginally. The inertial term is substantial, but changes sign over the time of the existence of the fully developed winter cell. Overall, apart from the inertial term, these findings match those for perpetual off-equatorial insolation.

Before the transition into the winter regime, the cell is in linear transient balance, with the Coriolis force on meridional momentum being balanced by vertical diffusion of zonal momentum and the inertial term. During the transition, however, the balance is primarily between the Coriolis force and the momentum transport of the mean circulation, which indicates that the cell approximately conserves angular momentum. This is supported by calculations of the local Rossby number: during the transition, local Rossby numbers in the upper branch above the cell center are close to one, implying that the stream function and angular momentum contours coincide there (Fig. 6, bottom panel; local Rossby numbers are masked close to the equator because $f$ is zero at $\varphi=0$ ).

Because the cell approximately conserves angular momentum during the transition into the winter regime, the cell responds directly to changes in the thermal driving (Schneider, 2006), and the mean-flow feedback described in Schneider and Bordoni (2008) explains the rapidity of the transition. Directly before the transition, at day 20 , the maximum in lowlevel potential temperature and the boundary between the southern and northern cell are at the equator $\left(\varphi_{\theta}=0 ; \varphi_{\Psi}=0\right)$. As the maximum solar heating moves farther poleward into the Northern Hemisphere, $\varphi_{\theta}$ and $\varphi_{\Psi}$ also move away from the equator into the summer hemisphere, which leads to a strengthening of the southern cell as expected from Lindzen and Hou (1988). On top of this, the advection of cold air in the lower branch of the intensifying southern cell pushes $\varphi_{\theta}$ and $\varphi_{\Psi}$ even further poleward, which leads to an additional strengthening of the circulation. Overall, the rapid transitions found here are consistent with the results of Schneider and Bordoni (2008) and Bordoni and Schneider (2010), showing that monsoon-like circulations are possible even in the absence of surface inhomogeneities provided the surface thermal inertia is sufficiently small.

The dynamics of the transition from the winter into the summer regime are qualitatively different from the dynamics during the transition into the winter regime. Momentum transport by the mean circulation is weak, leading to small local Rossby numbers in the upper branch of the cell (Fig. 6, bottom panel; Fig. 9, left panel). Instead, vertical diffusion of zonal momentum and the inertial term dominate the zonal momentum balance at the cell center, with opposing contributions. In particular, the inertial term prolongs the transition into the summer regime as its contribution to the cell strength is negative at the beginning but positive at the end of the transition. This explains why the transition into the summer regime is slow, in contrast to the the rapid transition into the winter regime for which the inertial term is small.

Vertical diffusion of meridional momentum is substantial throughout the winter regime and reaches similar values as for the perpetual off-equatorial insolation. Vertical diffusion of meridional momentum is especially large during the transition into and out of the winter regime, when the maximum of solar surface heating is close to the center of the winter cell and vertical stability is low (not shown). For the same reason, vertical diffusion of meridional momentum is slightly smaller during the solstice period when the solar insolation maximum is at the pole, which leads to higher vertical stability at the cell center and lower eddy viscosities. Nevertheless, vertical diffusion of meridional momentum mixes meridional momentum between the upper and lower branches of the winter cell at all times, consistent with its effect for perpetual off-equatorial insolation.

\subsection{Impact of vertical diffusion on the strength of the Hadley circulation}

In this subsection, I suppress vertical diffusion of momentum in the upper Hadley cell branch in simulations with seasonally varying insolation. I use the same approach as for perpetual off-equatorial insolation in Sect. 3.2 and for equinox insolation.

The Hadley circulation intensifies by a factor of 2 to 3 when vertical diffusion of momentum is suppressed as is summarized for the winter cell in Table 3; values for the summer cell are not given, as the latter collapses during solstice. The intensification results from the suppression of vertical diffusion of meridional momentum, whereas suppressing vertical diffusion of zonal momentum only has a weak effect.

Figure 9 (right panel) shows the strength of the winter cell and its decomposition by means of the zonal momentum budget for the simulation U0V0T1. Results for the simulation U0V0T0 are similar. Vertical diffusion of momentum neither affects the square-wave dependence of the winter cell strength on time nor the timing of the transitions. The latter likely is due to the fact that low-level eddy viscosities remain similar (Schneider and Bordoni, 2008; Bordoni and Schneider, 2010). When vertical diffusion of momentum is suppressed, the transition into the winter regime remains rapid with a timescale of around 15 days, which is not surprising given that the transition into the winter regime is dominated by the mean circulation and vertical diffusion is small during the transition. Suppressing vertical diffusion of momentum leads to a slightly faster transition out of the winter regime compared to the simulation with active 

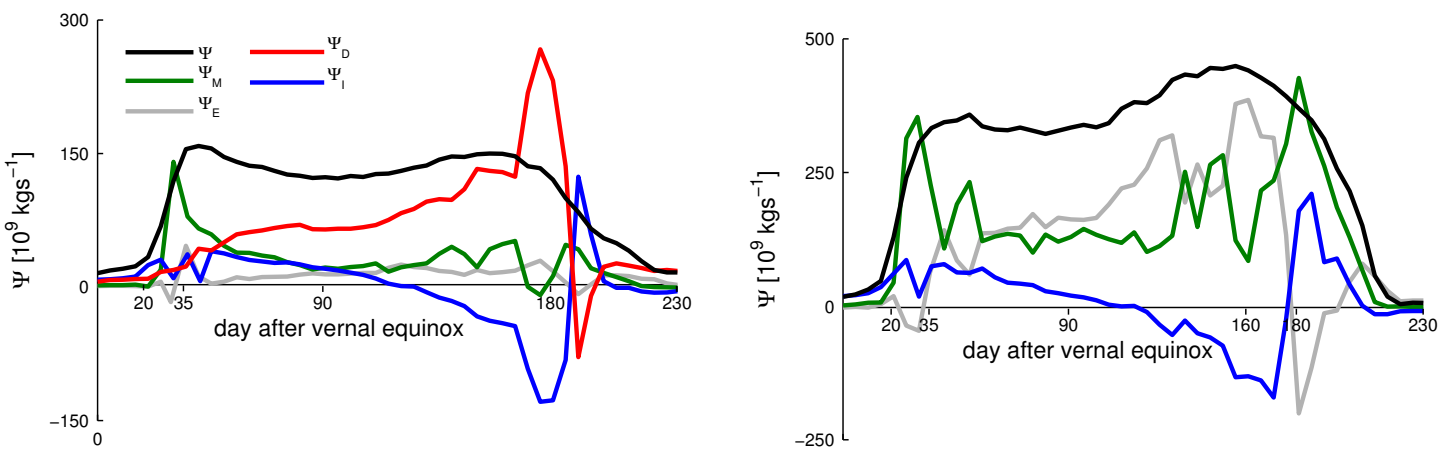

Fig. 9. Strength of the winter cell $(\Psi)$ for seasonally varying insolation as a function of time, and decomposition of $\Psi$ into contributions from the mean circulation $\left(\Psi_{\mathrm{M}}\right)$, eddies $\left(\Psi_{\mathrm{E}}\right)$, vertical diffusion $\left(\Psi_{\mathrm{D}}\right)$, and inertia $\left(\Psi_{\mathrm{I}}\right)$. Left panel: standard simulation (U1V1T1). Right panel: simulation with suppressed vertical diffusion of zonal and meridional momentum (U0V0T1).

Table 3. Strength of the winter cell for seasonally varying insolation. Values represent the stream function maximum of the southern cell averaged between day 35 and 160 in units of $10^{9} \mathrm{~kg} \mathrm{~s}^{-1}$.

\begin{tabular}{lc}
\hline Simulation & Winter cell strength \\
\hline STD & 136 \\
U0V0T1 & 375 \\
U0V0T0 & 246 \\
U0V1T1 & 178 \\
U0V1T0 & 143 \\
U1V0T1 & 380 \\
U1V0T0 & 307 \\
\hline
\end{tabular}

vertical diffusion (60 days compared to 75 days). To some extent this is because the winter cell is closer to the angularmomentum conserving limit when vertical diffusion of momentum is suppressed, so that the mean-flow feedback that causes the rapid transition into the winter regime can also operate during the transition out of the winter regime. However, the inertial terms causes the transition out of the winter regime to be markedly slower than the transition into the winter regime also when vertical diffusion of momentum is suppressed. Moreover, regarding the strength of the developed winter cell, suppressing vertical diffusion allows eddies to contribute substantially and even to dominate between day 130 to 160 , in contrast to their only marginal contribution when vertical diffusion of momentum is active.

In summary, the results for seasonally varying insolation corroborate those for perpetual off-equatorial and equinox insolation. They demonstrate that independent of the specified solar insolation, the net effect of vertical diffusion of momentum is to decelerate the Hadley cell due to mixing of meridional momentum between the upper and lower branches of the circulation.

\section{Impact of the Hadley circulation strength on the tropical hydrological cycle}

From the perspective of atmospheric dynamics the Snowball Earth atmosphere is a dry atmosphere, with a hydrological cycle that is greatly suppressed with respect to Earth's modern climate. Even so, the Snowball Earth hydrological cycle impacts the flow of sea-ice glaciers and determines the distribution of snow, both of which are important for the Snowball Earth climate and its deglaciation (cf. Sect. 1). In this section I therefore study how differences in the strength of the Hadley circulation caused by differences in the treatment of vertical diffusion affect the hydrological cycle.

The tropical annual-mean precipitation minus evaporation $(P-E)$ pattern exhibits net evaporation in the region around the equator and net precipitation in the subtropics. This pattern is reversed to modern conditions, while a similar pattern has been reported for Titan (Mitchell, 2008; Schneider et al., 2012). The pattern robustly emerges in Snowball simulations (Abbot et al., 2013) and results from the rapid seasonal transitions of the Hadley circulation, which imply that the ascent region in which precipitation outweighs evaporation is almost always located several degrees off the equator.

While the width of the equatorial net evaporation does not show any systematic variation with the strength of the Hadley circulation, the magnitude of the annual-mean $P-E$ pattern scales linearly with the strength of the winter cell. The linear scaling also holds for simulations with perpetual offequatorial insolation, which is expected because the annualmean pattern results from the superposition of the two opposite seasonal patterns. Thus, the linear scaling of the annualmean pattern can be understood from the linear scaling of the seasonal pattern, which in turn can be understood from the moisture equation as is shown in the following. Analogous approaches have been used to study the response of the present-day Earth's hydrological cycle to global warming (Chou and Neelin, 2004; Held and Soden, 2006). 

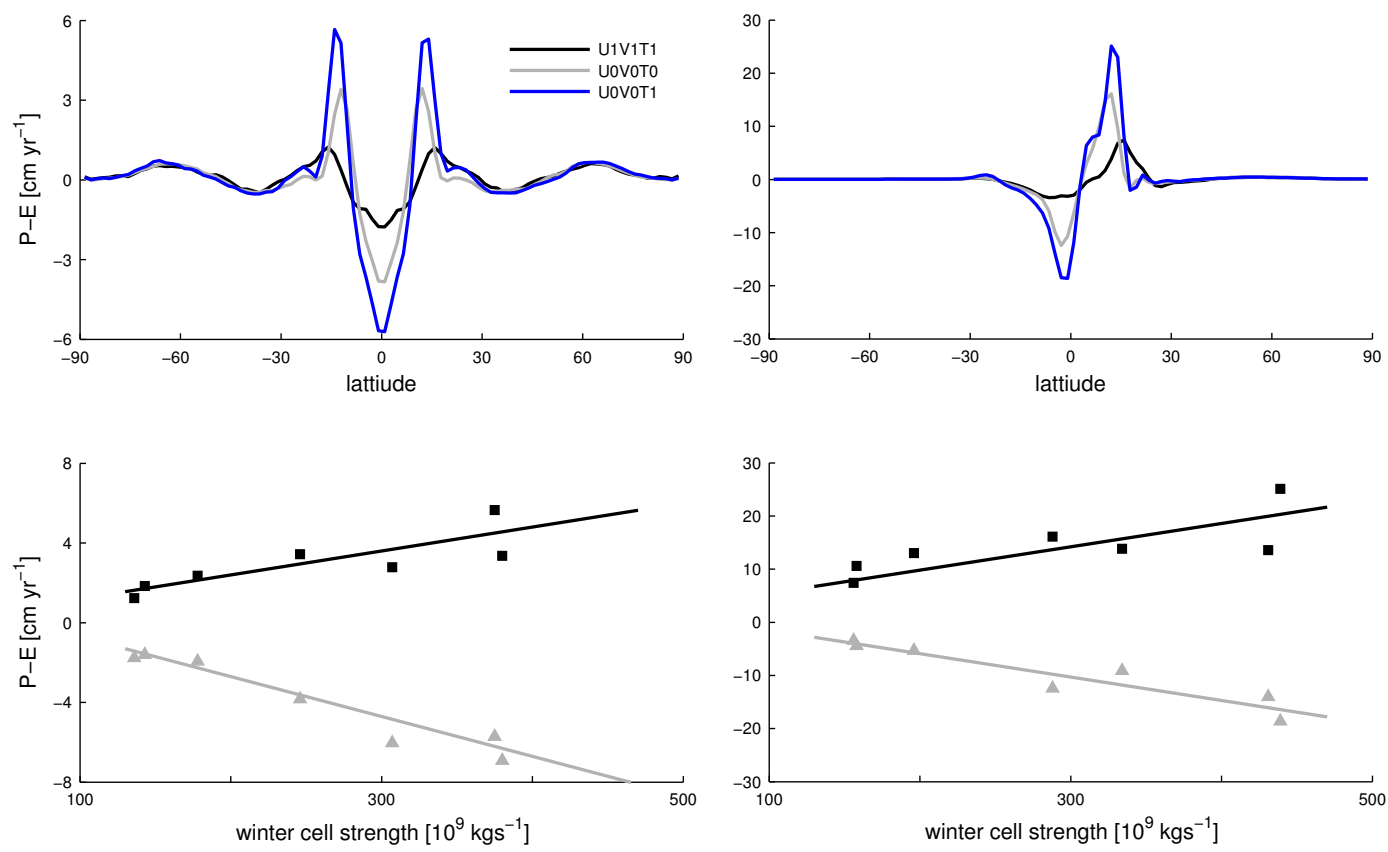

Fig. 10. Top panel: tropical pattern of precipitation minus evaporation $(P-E)$ for simulations with seasonally varying insolation (left) and perpetual off-equatorial insolation (right) and different treatment of vertical diffusion of momentum. Bottom panel: peak values of the precipitation minus evaporation pattern versus strength of the winter cell. Triangles show the equatorial minimum, squares the maximum at around $10-15^{\circ}$ latitude. The peak values scale linearly with the strength of the winter cell.

Assuming steady-state conditions, the vertical integral of the zonal-mean moisture equation reads

$\overline{P-E}=\int_{0}^{p_{s}} \nabla \cdot(\overline{q v}) \mathrm{d} p=\frac{1}{a \cos \varphi} \int_{0}^{p_{s}} \frac{\partial \overline{q v} \cos \varphi}{\partial \varphi} \mathrm{d} p$.

Overbars indicate a zonal mean, $q$ denotes specific humidity, $v$ the meridional wind, and the notation is standard otherwise. The decrease of temperatures with height and the ClausiusClapeyron equation entail that $q$ is concentrated in the planetary boundary layer (BL). Thus, the vertical integral can be restricted to the planetary boundary layer, which leads to the following scaling of $P-E$ :

$\overline{P-E} \propto \nabla \cdot\left(\overline{q_{\mathrm{BL}} v_{\mathrm{BL}}}\right)$.

Here, $q_{\mathrm{BL}}$ and $v_{\mathrm{BL}}$ represent boundary layer values of $v$ and $q$. Because the tropical circulation is dominated by its zonalmean component, one can further write

$\overline{P-E} \propto \nabla \cdot\left(\overline{q_{\mathrm{BL}}} \overline{v_{\mathrm{BL}}}\right)$.

As the meridional mass flux in the boundary layer is proportional to the Hadley cell strength, $H$, we can relate $\frac{P}{P-E}$ to $H$,

$\overline{P-E} \propto \nabla \cdot\left(\overline{q_{\mathrm{BL}}} H\right)$.

Finally, in the presented simulations changes in the vertical diffusion of momentum lead to strong changes in the
Hadley circulation strength but do not substantially affect surface temperatures and boundary-layer humidity. Consequently, changes in $P-E$ scale with changes in the Hadley cell,

$\delta \overline{P-E} \propto \nabla \cdot\left(\overline{q_{\mathrm{BL}}} \overline{\delta H}\right)$.

This explains the linear scaling shown in Fig. 10.

\section{Conclusions}

In this paper, I study the dynamics of the Hadley circulation of a Snowball Earth atmosphere. To this end, I use a comprehensive atmospheric general circulation model in hard Snowball Earth boundary conditions, which leads to an essentially dry atmosphere. Doing so offers a test to what extent dry theories and idealized models capture the dynamics of realistic dry Hadley circulations. The paper is motivated by and extends a previous study conducted for equinox insolation (Voigt et al., 2012). Here, perpetual off-equatorial and seasonally varying insolation is used.

The main result of this paper is that vertical diffusion of momentum is fundamental to the dynamics of the Snowball Earth Hadley circulation. This is illustrated in the analysis of the zonal and meridional momentum budgets. Strong vertical diffusion is present in simulations with perpetual off-equatorial as well as seasonally varying insolation. Together with the equinox result of Voigt et al. (2012), this 
demonstrates that the presence of strong vertical diffusion of momentum is independent of where the maximum solar heating is located.

The presence of strong vertical diffusion results from the strong surface sensible heat and buoyancy fluxes. It appears that strong vertical diffusion in the region of the Hadley circulation is difficult to avoid in dry atmospheres, an inference that is supported by the Snowball Earth simulations presented in Abbot et al. (2013), who used six comprehensive atmospheric general circulation models different from the one used here. In all of these models, and independent of the atmospheric $\mathrm{CO}_{2}$ concentration and surface temperatures, local Rossby numbers were below 0.5 in many parts of the upper branch of the winter cell, in particular above its center. Because easterlies shield the center of the winter cell from mid-latitude eddies and stream lines are nearly horizontal there, the low Rossby numbers indicate the presence of substantial vertical diffusion of momentum. This suggests that differences in the strength of the winter cell between these models might, at least partly, be explained by differences in the models' treatment of vertical diffusion of momentum. Nevertheless, studies with eddy-resolving models are needed to better constrain the exact strength of vertical diffusion.

Vertical diffusion of momentum strongly impacts the strength of the Hadley circulation. Vertical diffusion weakens the circulation by mixing meridional momentum between its upper and lower branches. Consequently, neglecting vertical diffusion of momentum leads to a two to three times stronger circulation, with the associated changes in the circulation leaving a direct imprint on the tropical hydrological cycle. An important implication of this result is that theories for Snowball Earth Hadley circulations, and realistic dry Hadley circulations in general, ought to take into account vertical diffusion of momentum, although this might be difficult because of the small-scale nature of vertical diffusion. Moreover, the results suggest that the scaling laws for dry Hadley circulations derived in dry theories and idealized atmosphere models that neglect vertical diffusion of momentum (e.g. Held and Hou, 1980; Walker and Schneider, 2006; Caballero et al., 2008) might not hold in Snowball Earth atmospheres. This should not be necessarily interpreted as a failure of these theories and idealized models, as they were often developed to capture the dynamics of present-day Earth Hadley circulations, for which surface sensible heat and dry buoyancy fluxes are comparably small and vertical diffusion does not play a dominant role. Nevertheless, the fact that these dry theories and idealized models do not take into account vertical diffusion limits their applicability to the Snowball Earth atmosphere, as well as to realistic dry atmospheres in general.
Acknowledgements. Dorian Abbot, Simona Bordoni and Tapio Schneider as well as an anonymous reviewer are thanked for comments on the manuscript. This research was made possible through funding from the German Science Foundation under grant agreement VO 1765/3-1 and through support of the Max Planck Society for the Advancement of Science. Computing resources were provided by the German Climate Computing Center (DKRZ), Hamburg.

Edited by: V. Lucarini

\section{References}

Abbot, D. S. and Halevy, I.: Dust Aerosol Important for Snowball Earth Deglaciation, J. Climate, 23, 4121-4132, doi:10.1175/2010JCLI3378.1, 2010.

Abbot, D. S. and Pierrehumbert, R. T.: Mudball: Surface dust and Snowball Earth deglaciation, J. Geophys. Res.-Atmos., 115, D03104, doi:10.1029/2009JD012007, 2010.

Abbot, D. S., Eisenman, I., and Pierrehumbert, R. T.: The importance of ice vertical resolution for Snowball climate and deglaciation, J. Climate, 23, 6100-6109, 2010.

Abbot, D. S., Voigt, A., and Koll, D.: The Jormungand Global Climate State and Implications for Neoproterozoic Glaciations, J. Geophys. Res., 116, D18103, doi:10.1029/2011JD015927, 2011.

Abbot, D. S., Voigt, A., Branson, M., Pierrehumbert, R. T., Pollard, D., Le Hir, G., and Koll, D. D. B.: Clouds and Snowball Earth deglaciation, Geophys. Res. Lett., 39, L20711, doi:10.1029/2012GL052861, 2012.

Abbot, D. S., Voigt, A., Li, D., Hir, G. L., Pierrehumbert, R. T., Branson, M., Pollard, D., and Koll, D.: Robust elements of Snowball Earth atmospheric circulation and oases for life, J. Geophys. Res.-Atmos., 118, 6017-6027, doi:10.1002/jgrd.50540, 2013.

Bordoni, S. and Schneider, T.: Regime Transitions of Steady and Time-Dependent Hadley Circulations: Comparison of Axisymmetric and Eddy-Permitting Simulations, J. Atmos. Sci., 67, 1643-1654, doi:10.1175/2009JAS3294.1, 2010.

Brandt, R. E., Warren, S. G., Worby, A. P., and Grenfell, T. C.: Surface albedo of the antarctic sea ice zone, J. Climate, 18, 36063622, doi:10.1175/JCLI3489.1, 2005.

Caballero, R., Pierrehumbert, R. T., and Mitchell, J. L.: Axisymmetric, nearly inviscid circulations in non-condensing radiativeconvective atmospheres, Q. J. Roy. Meteorol. Soc., 134, 12691285, doi:10.1002/qj.271, 2008.

Campbell, A. J., Waddington, E. D., and Warren, S. G.: Refugium for surface life on Snowball Earth in a nearly-enclosed sea? A first simple model for sea-glacier invasion, Geophys. Res. Lett., 38, L19502, doi:10.1029/2011GL048846, 2011.

Charney, J. G.: A further note on large-scale motions in the Tropics, J. Atmos. Sci., 26, 182-185, doi:10.1175/15200469(1969)026<0182:AFNOLS>2.0.CO;2, 1969.

Chou, C. and Neelin, J.: Mechanisms of global warming impacts on regional tropical precipitation, J. Climate, 17, 2688-2701, doi:10.1175/1520-0442(2004)017<2688:MOGWIO>2.0.CO;2, 2004. 
Dadic, R., Mullen, P. C., Schneebeli, M., Brandt, R. E., and Warren, S. G.: Effects of bubbles, cracks, and volcanic tephra on the spectral albedo of bare ice near the Transantarctic Mountains: implications for sea-glaciers on Snowball Earth, J. Geophys. Res.Earth, 118, 1658-1676, doi:10.1002/jgrf.20098, 2013.

Held, I. M. and Hou, A. Y.: Non-Linear axially-symmetric circulations in a nearly inviscid atmosphere, J. Atmos. Sci., 37, 515533,1980

Held, I. M. and Soden, B. J.: Robust responses of the hydrological cycle to global warming, J. Climate, 19, 5686-5699, doi:10.1175/JCLI3990.1, 2006.

Hoffman, P. F. and Schrag, D.: Snowball earth, Scientific American, 282, 68-75, 2000.

Hoffman, P. F., Kaufman, A. J., Halverson, G. P., and Schrag, D. P.: A Neoproterozoic snowball earth, Science, 281, 13421346, doi:10.1126/science.281.5381.1342, 1998.

Kirschvink, J. L.: The Proterozoic Biosphere, in: Late Proterozoic low-latitude global glaciation: The snowball Earth, edited by: Schopf, J. W. and Klein, C., Cambridge University Press, Cambridge, UK, 51-52, 1992.

Le Hir, G., Donnadieu, Y., Krinner, G., and Ramstein, G.: Toward the snowball earth deglaciation..., Clim. Dynam., 35, 285-297, doi:10.1007/s00382-010-0748-8, 2010.

Lindzen, R. and Hou, A.: Hadley circulations for zonally averaged heating centered off the equator, J. Atmos. Sci., 45, 2416-2427, doi:10.1175/1520-0469(1988)045<2416:HCFZAH>2.0.CO;2, 1988.

Mitchell, J. L.: The drying of Titan's dunes: Titan's methane hydrology and its impact on atmospheric circulation, J. Geophys. Res.-Planets, 113, E08015, doi:10.1029/2007JE003017, 2008.

Pierrehumbert, R., Abbot, D., Voigt, A., and Koll, D.: Climate of the Neoproterozoic, Annu. Rev. Earth Pl. Sc., 39, 417-460, doi:10.1146/annurev-earth-040809-152447, 2011.

Schneider, T.: The general circulation of the atmosphere, Annu. Rev. Earth Pl. Sc., 34, 655-688, 2006.

Schneider, T. and Bordoni, S.: Eddy-mediated regime transitions in the seasonal cycle of a Hadley circulation and implications for monsoon dynamics, J. Atmos. Sci., 65, 915-934, 2008.
Schneider, T., Graves, S. D. B., Schaller, E. L., and Brown, M. E.: Polar methane accumulation and rainstorms on Titan from simulations of the methane cycle, Nature, 481, 58-61, doi:10.1038/nature10666, 2012.

Tziperman, E., Abbot, D. S., Ashkenazy, Y., Gildor, H., Pollard, D., Schoof, C. G., and Schrag, D. P.: Continental constriction and oceanic ice-cover thickness in a Snowball-Earth scenario, J. Geophys. Res.-Oceans, 117, doi:10.1029/2011JC007730, 2012.

Voigt, A. and Abbot, D. S.: Sea-ice dynamics strongly promote Snowball Earth initiation and destabilize tropical sea-ice margins, Clim. Past, 8, 2079-2092, doi:10.5194/cp-8-2079-2012, 2012.

Voigt, A. and Marotzke, J.: The transition from the present-day climate to a modern Snowball Earth, Clim. Dynam., 35, 887-905, doi:10.1007/s00382-009-0633-5, 2010.

Voigt, A., Held, I. M., and Marotzke, J.: Hadley Cell Dynamics in a Virtually Dry Snowball Earth Atmosphere, J. Atmos. Sci., 69, 116-128, doi:10.1175/JAS-D-11-083.1, 2012.

Walker, C. C. and Schneider, T.: Response of idealized Hadley circulations to seasonally varying heating, Geophys. Res. Lett., 32, L06813, doi:10.1029/2004GL022304, 2005.

Walker, C. C. and Schneider, T.: Eddy influences on Hadley circulations: Simulations with an idealized GCM, J. Atmos. Sci., 63, 3333-3350, 2006.

Warren, S. G. and Brandt, R. E.: Comment on "Snowball Earth: A thin-ice solution with flowing sea glaciers" by David Pollard and James F. Kasting, J. Geophys. Res.-Oceans, 111, C09016, doi:10.1029/2005JC003411, 2006.

Webster, P. J. and Holton, J. R.: Cross-equatorial response to mid-latitude forcing in a zonally varying basic state, J. Atmos. Sci., 39, 722-733, doi:10.1175/15200469(1982)039<0722:CERTML>2.0.CO;2, 1982.

Yang, J., Peltier, W., and Hu, Y.: The initiation of modern "Soft Snowball" and "Hard Snowball" climates in CCSM3, Part I: the influences of solar luminosity, $\mathrm{CO}_{2}$ concentration, and the sea ice/snow albedo parameterization, J. Climate, 25, 2711-2736, 2012a.

Yang, J., Peltier, W. R., and Hu, Y.: The Initiation of modern "Soft Snowball" and "Hard Snowball" climates in CCSM3, Part II: climate dynamic feedbacks, J. Climate, 25, 2737-2754, 2012 b. 